\title{
A NEW CORRECTION MAGNET PACKAGE FOR THE FERMILAB BOOSTER SYNCHROTRON *
}

\author{
V.S. Kashikhin\#, J.A. Carson, D.J. Harding, J.R. Lackey, A. Makarov, W. Pellico, E.J. Prebys \\ Fermi National Accelerator Laboratory, Batavia, IL 60510
}

\begin{abstract}
Since its initial operation over 30 years ago, most correction magnets in the Fermilab Booster Synchrotron have only been able to fully correct the orbit, tunes, coupling, and chromaticity at injection $(400 \mathrm{MeV})$. We have designed a new correction package, including horizontal and vertical dipoles, normal and skew quadrupoles, and normal and skew sextupoles, to provide control up to the extraction energy $(8 \mathrm{GeV})$. In addition to tracking the $15 \mathrm{~Hz}$ cycle of the main, combined function magnets, the quadrupoles and sextupoles must swing through their full range in $1 \mathrm{~ms}$ during transition crossing. The magnet is made from 12 water-cooled racetrack coils and an iron core with 12 poles, dramatically reducing the effective magnet air gap and increasing the corrector efficiency. Magnetic field analyses of different combinations of multipoles are included.
\end{abstract}

\section{INTRODUCTION}

The current Booster correction system is relatively weak because the correctors do not have an iron core and are only air cooled. A test of this corrector showed that it has a low maximum temperature margin and very quickly overheated at larger current in the coils. Nevertheless, there is a need to increase the corrector strength by 10 times for the horizontal trim, by 50 times for the vertical trim, and by 3.6 times for the quadrupole. [1] The existing system cannot run hard enough to adequately control beam position or tune through the accelerating cycle without corrector coils overheating.

Many multipole correctors have been designed, manufactured and tested for particle accelerators, for example, Daresbury [2], NSLS [3], TRIUMF [4]. The most attractive way is to combine all needed coils in one package, saving space between the main magnets, which is usually very tight, and providing better distribution of power buses in the accelerator tunnel.

\section{CORRECTOR MAGNET DESIGN}

The Fermilab Booster includes a corrector package in each of the 48 sub-periods. Each new corrector package includes:

- Horizontal and Vertical Dipole

- Normal and Skew Quadrupoles

- Normal and Skew Sextupoles.

The main Booster bus is excited with a $15 \mathrm{~Hz}$ sine wave current on top of a $50 \%$ peak current DC offset. The trims will usually follow roughly the same excitation

\footnotetext{
* Work supported by the United States Department of Energy under Contract No. DE-AC02-76CH03000

${ }^{\#}$ kash ffnal onv
}

curve. The good field region is a circle of $25.4 \mathrm{~mm}$ radius with field quality better than $1 \%$. The quadrupole trims must be able to induce a 0.1 unit tune shift at the highest fields. It corresponds to the quadrupole field change from full field plus to full field minus in $\sim 1 \mathrm{~ms}$.

\section{Magnet Parameters and Concept}

A 12-pole iron dominated magnet was chosen as the base line for the corrector design. Such configuration is the best to generate normal and skew dipole, quadrupole and sextupole fields. At the same time, iron poles greatly reduce the required ampere-turns in the coils and nearly eliminate the dependence of the magnetic field on deviations in the coil position and geometry. The specified corrector parameters are shown in the Table 1. The six magnet windings will generate in the aperture normal and skew dipole, quadrupole and sextupole fields. All of them will be powered separately, providing independent multipole field correction.

Table 1: Corrector Specifications

\begin{tabular}{|c|c|c|c|}
\hline Type & $\begin{array}{c}\text { Integrated } \\
\text { field or } \\
\text { gradient }\end{array}$ & $\begin{array}{c}\text { Aperture } \\
\text { field or } \\
\text { gradient }\end{array}$ & $\begin{array}{c}\text { Field, T at } \\
\mathbf{2 5 . 4} \mathbf{~ m m} \\
\text { radius }\end{array}$ \\
\hline $\begin{array}{c}\text { Horizontal } \\
\text { dipole }\end{array}$ & $0.009 \mathrm{~T}-\mathrm{m}$ & $0.045 \mathrm{~T}$ & 0.045 \\
\hline $\begin{array}{c}\text { Vertical } \\
\text { dipole }\end{array}$ & $0.015 \mathrm{~T}-\mathrm{m}$ & $0.075 \mathrm{~T}$ & 0.075 \\
\hline $\begin{array}{c}\text { Normal } \\
\text { quadrupole }\end{array}$ & $0.08 \mathrm{~T}$ & $0.4 \mathrm{~T} / \mathrm{m}$ & 0.01016 \\
\hline $\begin{array}{c}\text { Skew } \\
\text { quadrupole }\end{array}$ & $0.008 \mathrm{~T}$ & $0.04 \mathrm{~T} / \mathrm{m}$ & 0.001016 \\
\hline $\begin{array}{c}\text { Normal } \\
\text { sextupole }\end{array}$ & $1.41 \mathrm{~T} / \mathrm{m}$ & $7.05 \mathrm{~T} / \mathrm{m}^{2}$ & 0.00455 \\
\hline $\begin{array}{c}\text { Skew } \\
\text { sextupole }\end{array}$ & $1.41 \mathrm{~T} / \mathrm{m}$ & $7.05 \mathrm{~T} / \mathrm{m}^{2}$ & 0.00455 \\
\hline
\end{tabular}

The magnet cross-sections are shown in Figures 1 and 2. Each color corresponds to the windings for one multipole. The coil packages have a racetrack configuration. This type of coil is simpler to manufacture than shell type coils. Two versions of coils were investigated. The first would be wound from copper conductor with a hole for direct water cooling. The second would be made from a smaller, solid conductor with a cooling pipe for indirect water-cooling. Although direct cooling provides higher current density at lower coil temperature, the reduced current ( $50 \mathrm{~A}$ vs $200 \mathrm{~A}$ ) of the solid conductor determined its eventual selection.

Each coil package includes either three or five coils, with those coils bussed together to produce the desired 
fields. Despite the complexity, there are only two types of package, having 18 or 20 turns for $200 \mathrm{~A}$ coil version Figure 1 and 72 or 80 turns for 50A shown in Figure 2.

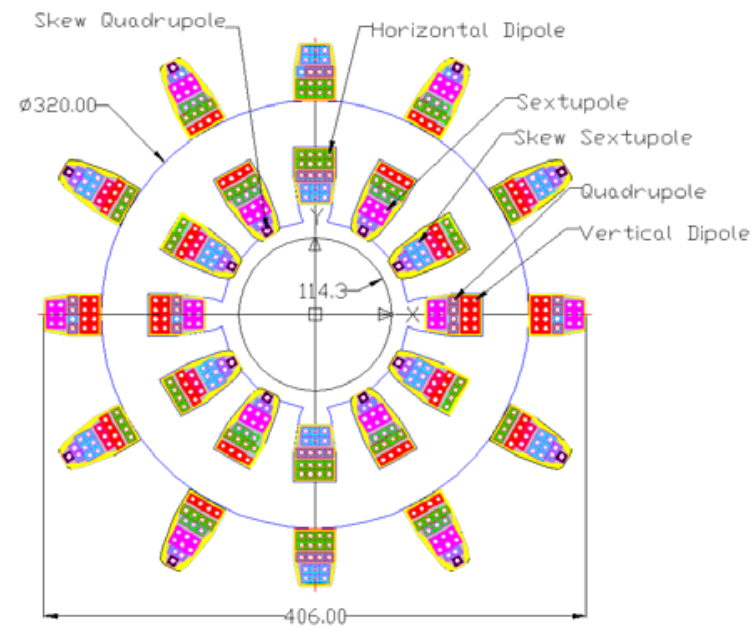

Figure 1: Corrector with direct water-cooling.

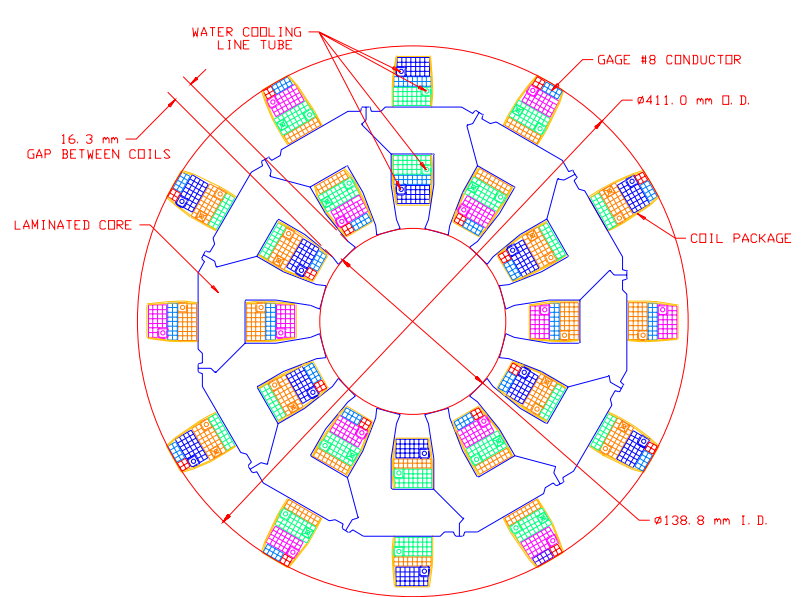

Figure 2: Corrector with indirect water-cooling.

\section{Magnetic Design}

In order to generate field with good quality, the turns should be distributed as $\operatorname{Cos}(\mathbf{n} \boldsymbol{\theta})$ around the aperture, where $\mathbf{n}$ is equal $1,2,3$ for dipole, quadrupole and sextupole windings respectively. The distribution of turns for the $200 \mathrm{~A}$, direct cooling version is shown in Figure 3. This diagram shows, for example, that the right horizontal coil should be 6 turns of sextupole, 4 turns of quadrupole and 8 turns of vertical dipole winding.

Magnetic fields were calculated using OPERA-2d [5]. Table 2 presents the calculation results for singly powered windings to estimate the field quality and aperture fields. The yoke saturation effects were calculated when all windings were powered at maximum $200 \mathrm{~A}$ current (see Figure 4) for the direct cooling model. In this case the maximum field density in the yoke was $0.78 \mathrm{~T}$. It should be noted that end fields would increase this value.

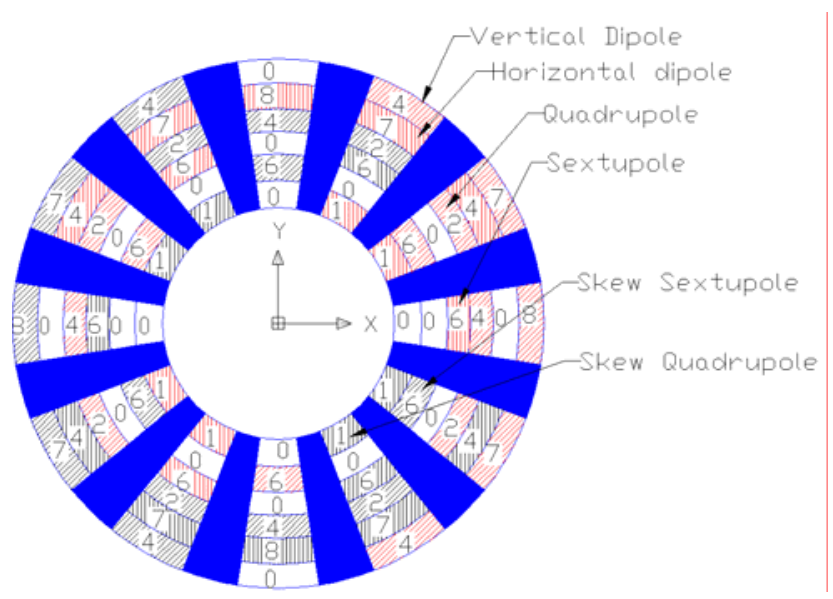

Figure 3: Distribution of turns for the 200 A version.

Table 2: Field calculation results.

\begin{tabular}{|c|c|c|c|}
\hline Type & $\begin{array}{c}\text { Aperture } \\
\text { field or } \\
\text { gradient }\end{array}$ & $\begin{array}{c}\text { Field } \\
\text { homogeneity } \\
\text { at 25.4 mm } \\
\text { radius }\end{array}$ & $\begin{array}{c}\text { Yoke } \\
\text { max. } \\
\text { field, T }\end{array}$ \\
\hline $\begin{array}{c}\text { Horizontal } \\
\text { dipole }\end{array}$ & $0.054 \mathrm{~T}$ & $1.4 \times 10^{-4}$ & 0.44 \\
\hline $\begin{array}{c}\text { Vertical } \\
\text { dipole }\end{array}$ & $0.054 \mathrm{~T}$ & $1.4 \times 10^{-4}$ & 0.44 \\
\hline $\begin{array}{c}\text { Normal } \\
\text { quadrupole }\end{array}$ & $0.375 \mathrm{~T} / \mathrm{m}$ & $3.5 \times 10^{-3}$ & 0.15 \\
\hline $\begin{array}{c}\text { Skew } \\
\text { quadrupole }\end{array}$ & $0.11 \mathrm{~T} / \mathrm{m}$ & $2.5 \times 10^{-3}$ & 0.03 \\
\hline $\begin{array}{c}\text { Normal } \\
\text { sextupole }\end{array}$ & $7.8 \mathrm{~T} / \mathrm{m}^{2}$ & $1.1 \times 10^{-2}$ & 0.2 \\
\hline $\begin{array}{c}\text { Skew } \\
\text { sextupole }\end{array}$ & $7.8 \mathrm{~T} / \mathrm{m}^{2}$ & $1.1 \times 10^{-2}$ & 0.2 \\
\hline
\end{tabular}

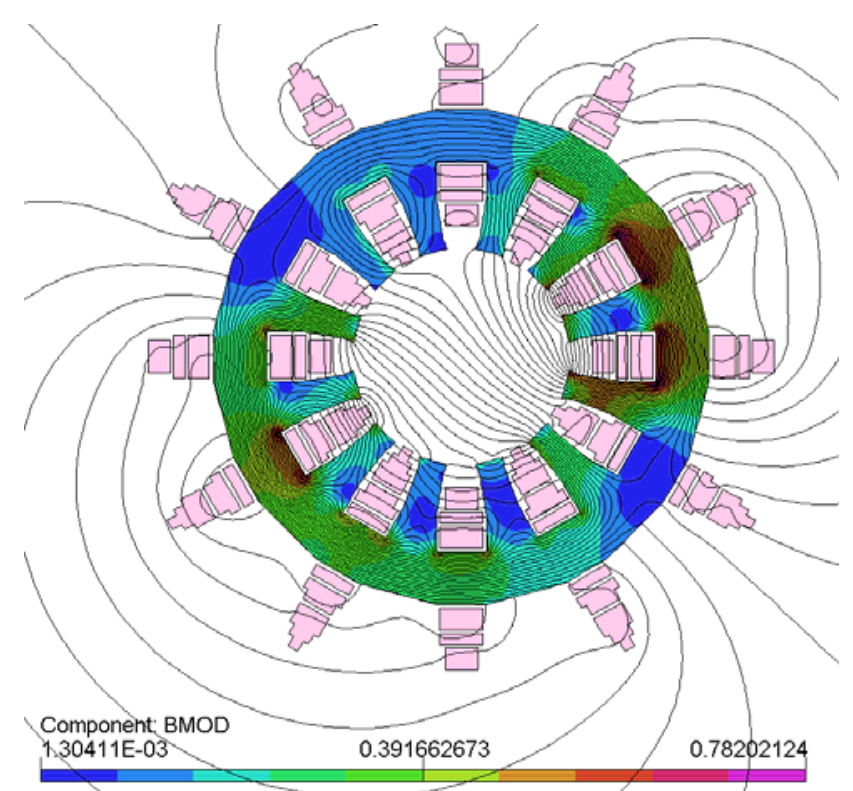

Figure 4: Flux density and flux line distribution at maximum current in all windings. 
The eddy current effects were estimated when the quadrupole winding in the magnet was ramped up to maximum field during $0.5 \mathrm{~ms}$. See Figure 5 . The eddy currents were calculated in the beam pipe and in the beam position monitor plates, modeled as the horizontal and vertical plates shown inside the beam pipe. The stainless steel conductivity was taken as $1.33 \times 10^{6} \mathrm{Ohm}-\mathrm{m}^{-1}$.

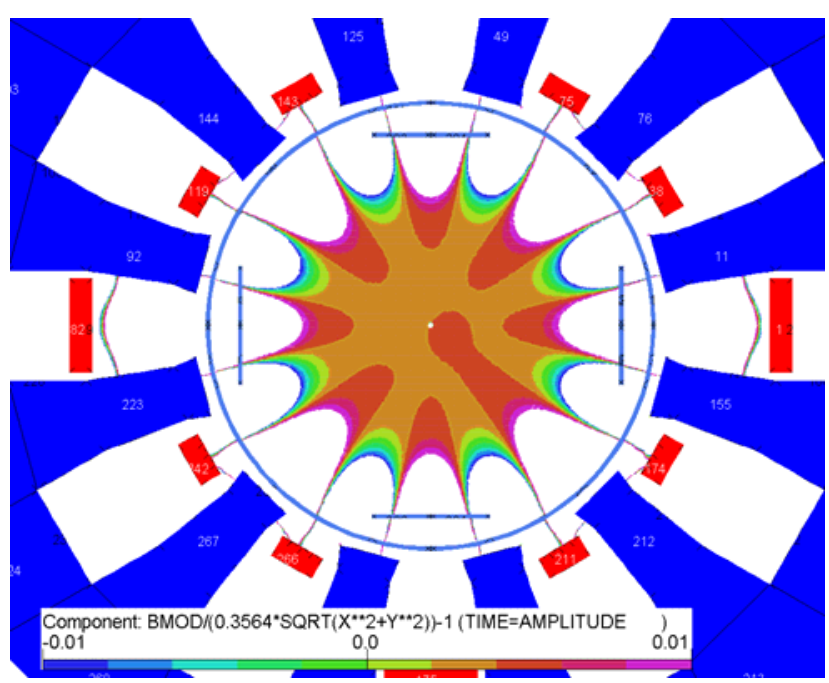

Figure 5: Field quality in the aperture after $0.5 \mathrm{~ms}$ ramp.

The transient magnetic field analysis showed that the field quality is in the range $+/-1 \%$ inside the area with radius $4 \mathrm{~cm}$.

\section{Mechanical Design}

Design work has begun based on the indirect cooling scheme. The corrector package will be assembled from 12 separately manufactured racetrack coil packages and 12 laminated poles. The laminated core length is $230 \mathrm{~mm}$. Each racetrack coil is wound separately, vacuum impregnated with epoxy and cured. The most challenging task is to make the large number of coil joints in the tight space between the coils. Most of the 12 coil packages consist of five individual coils, wound of $3.3 \mathrm{~mm} \times 3.3 \mathrm{~mm}$ copper conductor (10 leads) and two water lines, made of $6.35 \mathrm{~mm}$ x $6.35 \mathrm{~mm}$ copper tube (4 leads). The leads must be soldered and the water lines brazed, then both insulated, within the $16 \mathrm{~mm}$ gap between coils. Both ends of the magnet can be used for the coil leads, but all the water leads must be located on the same end of the magnet.

Because the normal quadrupole polarity must be switched in $1 \mathrm{~ms}$ during a gamma-t jump, the core laminations must be no more than $0.25 \mathrm{~mm}$ thick and insulated to reduce the eddy current effects.

\section{Corrector Prototype}

Several partial models are planned to address of the mechanical challenges, followed by a full prototype magnet. Production will start in 2006 and installations is planned for 2007. Interesting points of study include:
- $\quad$ Test the efficiency of indirect coil water-cooling in a few single coils.

- Verify the sufficiency of space between coils for magnet interconnections.

- Develop different tooling and manufacturing procedures.

- Measure the magnetic field quality and effective length of each field component.

- $\quad$ Test the quadrupole trim in pulsed mode.

The assembly technological model is shown in Fig. 6.

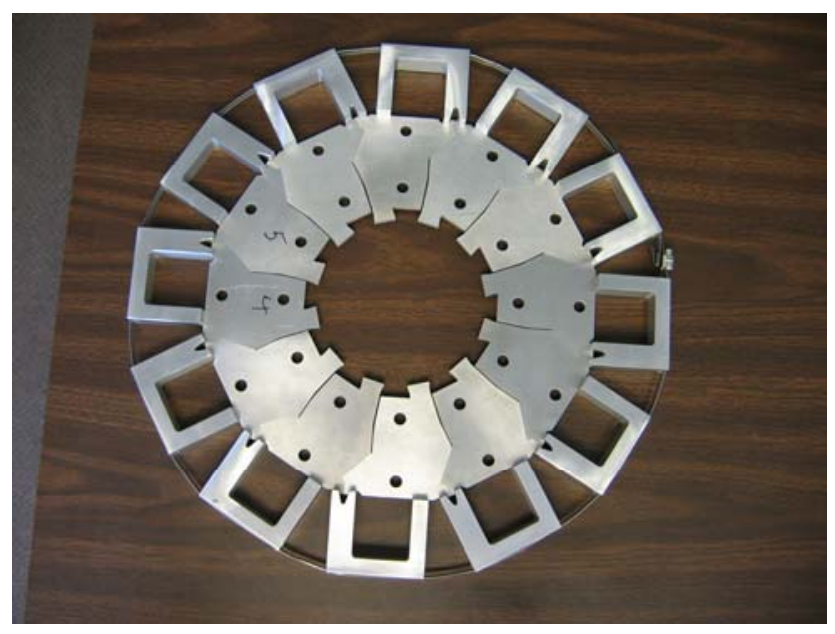

Figure 6: Trial assembly of 12 thin segments representing core-coil combinations with possible tooling.

\section{SUMMARY}

The new corrector packages for the Fermilab Booster are moving from conceptual design to prototyping. This corrector has following features:

- Combines all dipole, quadrupole and sextupole trims in one package.

- The element strengths allow full correction of the orbit, tunes and chromaticity through the entire acceleration cycle.

- Elements can switch polarity at full current in $1 \mathrm{~ms}$ to support a gamma-t jump.

\section{REFERENCES}

[1] E.J. Prebys, et al., "Booster Corrector System Specification”, Fermilab Beams-doc-1430, 2004

[2] R.P. Walker, "Design and Testing of Multipole Magnets for the Daresbury Synchrotron Radiation Source," IEEE Transactions on Magnetics, VOL. MAG-17, No. 5, September 1981, p. 1847.

[3] J. Krishnaswamy, et al., "Magnetic Measurements of the 12-Pole Trim Magnets for the $200 \mathrm{MeV}$ Compact Synchrotron XLS at the National Synchrotron Light Source,” PAC’91, May 1991, p. 2119.

[4] A.J. Otter, P.A. Reeve, "Combined AC Corrector Magnets,” PAC’93, May 1993, p. 2898.

[5] "Software for Electromagnetic Design, OPERA-2d," Vector Fields Limited, VF-02-04-A3, 2004. 